\title{
Nutritional strategies for post-exercise recovery: a review
}

\author{
Kelly L Pritchett (PhD, RD, CSSD) ${ }^{1}$ \\ Robert C Pritchett (PhD) ${ }^{1}$ \\ Philip Bishop (EdD) ${ }^{2}$ \\ ${ }^{1}$ Department of Health, Human Performance, and Nutrition, Central Washington University, Ellensburg, WA \\ ${ }^{2}$ Kinesiology Department, University of Alabama, Tuscaloosa, AL
}

\begin{abstract}
Finding the optimal nutrition regimen for enhanced recovery is fundamental in enhancing exercise training and performance. Therefore, research has aimed to examine post-exercise nutritional strategies for optimal recovery. Because muscle glycogen is the primary substrate utilised during high-intensity exercise, it must be replenished. Recent research has examined the effectiveness on recovery of adding protein to a post-exercise carbohydrate beverage. This review summarises and analyses the literature on nutritional strategies aimed at enhancing various indicators of post-exercise recovery: glycogen resynthesis, muscle damage and performance. Furthermore, the literature on Medline and Pubmed comparing the effectiveness of carbohydrate-only $(\mathrm{CHO})$ beverage with a carbohydrate:protein (CHO:PRO) beverage on maximising recovery was reviewed. The methods and results of studies regarding post-exercise nutritional strategies for recovery were analysed. Primary results of this review suggest that the optimal timing in regard to post-exercise nutritional strategies for maximal glycogen resynthesis is within the first $30 \mathrm{~min}$ utes after exercise. The literature suggests that $1.0-1.5 \mathrm{~g}_{\mathrm{kg}} \mathrm{k}^{-1} \mathrm{~h}^{-1}$ of carbohydrate ingested at 2-hour intervals after exercise for up to 6 hours may be optimal for recovery. The addition of protein to a post-exercise meal may supply additional amino acids necessary for muscle repair creating an anabolic condition.
\end{abstract}

\section{Introduction}

Athletes and sports dietitians have sought post-exercise nutritional strategies that will enhance muscle glycogen resynthesis after exercise, enhance recovery and maintain or improve the quality of future workouts or performances. ${ }^{1-3}$ Athletes may participate in one or more training sessions a day with anywhere from 6 to 24 hours of

\section{CORRESPONDENCE:}

Kelly Pritchett

Department of Health, Human Performance and Nutrition

400 East University Way

Central Washington University

Ellensburg, WA 98926

Tel: 205-887-1809

E-mail: Kkerr@cwu.edu recovery between workouts. ${ }^{3}$ A principal component of training for an elite athlete is to maximise training in order to increase potential for competition. Because full and often rapid recovery is necessary for optimal performance, ${ }^{2}$ athletes should practise nutritional strategies that maximise recovery.

Dietary recommendations for pre-competition nutritional strategies have been well established. ${ }^{1}$ Because muscle glycogen is the main fuel during intense exercise, replenishing muscle glycogen stores in the post-exercise recovery period is an important factor influencing recovery and performance. In addition, the timing and composition of a post-exercise meal is highly dependent upon the duration and intensity of the preceding exercise bout. ${ }^{4}$ Research regarding postexercise nutritional strategies has focused on timing of ingestion, type of $\mathrm{CHO}$ (solid v. liquid), amount of carbohydrate, presence of other nutrients (e.g. protein), and frequency of post-exercise feedings to determine the most effective way to enhance glycogen resynthesis. ${ }^{5}$ Research examining carbohydrate consumption during recovery periods of 4 hours or more suggests enhanced recovery and exercise performance which would be beneficial to athletes competing in events with short recovery periods (preliminary heats, finals) such as track and field, swimming, and multiple day events, such as the Tour de France. Guidelines regarding the optimal timing and amount of carbohydrate after exercise have been well established. ${ }^{3,4}$

This article will provide an overview and discussion of the research that focuses on the effects of $\mathrm{CHO}$ and $\mathrm{CHO}$ :PRO feedings after exercise on various indices of recovery, including muscle damage, glycogen resynthesis and exercise performance. Research has also examined the effectiveness of the addition of protein to a post-exercise carbohydrate beverage on recovery. In addition, this paper will review the existing guidelines for a post-exercise recovery meal, ${ }^{4}$ including timing and presence of other nutrients.

\section{Carbohydrate and recovery}

Muscle glycogen is the primary fuel source during high-intensity exercise and an important source during endurance exercise. Therefore, after prolonged intense exercise, post-exercise glycogen restoration plays a very important role in the recovery process. Because endogenous carbohydrate is a crucial but relatively limited fuel during high-intensity prolonged endurance exercise, it must be replenished. Post-exercise glycogen synthesis is highly dependent on the extent of glycogen depletion, as well as the type, duration and intensity of the exercise session. ${ }^{6}$ For up to 6 hours after exercise, the rate of muscle glycogen resynthesis is accelerated, and within 24 hours after exercise complete restoration of glycogen stores can occur when sufficient amounts of carbohydrate are consumed. ${ }^{1,7}$ Glycogen resynthesis after a glycogen-depleting exercise bout or endurance exercise occurs in two phases. The first phase, or the rapid phase, 
lasts anywhere from 30 to 60 minutes and is insulin independent due to the increased permeability of the muscle cell as a result of exercise-induced translocation of GLUT-4 (glucose transporter carrier protein-4) and plausibly an up-regulation of glycogen synthase. An increase in post-exercise glycogen synthase and exercise-induced increases in insulin sensitivity may be the potential mechanism responsible for the 2- to 4-hour period of enhanced glycogen resynthesis following exercise.

The literature indicates that a recovery meal consumed within 2 hours after exercise, compared with no feeding, is effective in improving recovery. ${ }^{8}$ Because complete muscle glycogen resynthesis can take as long as 24 hours, even under optimal conditions, studies have examined methods to increase the rate of muscle glycogen resynthesis. $^{9}$ Depending on the extent of glycogen depletion, consuming $1.0-1.5 \mathrm{~g} \mathrm{CHO} . \mathrm{kg}^{-1} \mathrm{~h}^{-1}$ immediately after exercise, and at 30-minute intervals for up to 6 hours after exercise, appears to be optimal for adequate glycogen resynthesis. ${ }^{1,4,10,11,25}$ On the other hand, if $\mathrm{CHO}$ intake is delayed by 2 hours, glycogen resynthesis rates have been found to be $45 \%$ lower. ${ }^{3,12}$

Intestinal absorption of glucose is possibly a rate-limiting factor for glycogen resynthesis when a large bolus of carbohydrate is consumed after exercise. ${ }^{13} \mathrm{CHO}$ supplementation $\left(\sim 1.0 \mathrm{~g} \cdot \mathrm{kg}^{-1} \mathrm{~h}^{-1}\right)$ provided at frequent intervals (15 - 60-minute intervals) after exercise has been suggested to be more effective than a large bolus in maintaining higher blood glucose levels, thereby resulting in increased muscle glycogen restoration. 1,3
The majority of the research has examined the effect of a postexercise recovery beverage given in 1-hour increments. However, little research has examined the effects of providing a post-exercise beverage at more frequent intervals versus a large bolus feeding. Research regarding glycogen resynthesis rates is equivocal when different amounts of carbohydrate were consumed after exercise. ${ }^{1,6}$ Ingesting a carbohydrate beverage at more frequent intervals (30-minute intervals) has been associated with enhanced glycogen resynthesis rates. ${ }^{1,12,14}$ Van Loon et al. found that an increase in post-exercise consumption of carbohydrate from 0.8 to $1.2 \mathrm{~g}^{\mathrm{kg}} \mathrm{kg}^{-1} \mathrm{~h}^{-1}$ taken at 30 -minute intervals increased muscle glycogen synthesis rates (16.6 v. 35.4 mmol. $\mathrm{kg}^{-1}$. $\left.d w \cdot h^{-1}\right)$ in 8 trained cyclists following a glycogen depletion cycling trial. $^{6}$ The majority of studies that have found no effect on glycogen resynthesis with increased carbohydrate intake post exercise have supplemented at 2-hour intervals. ${ }^{12,14}$ Recent research suggests that 2-hour intervals may not be optimal for increasing muscle glycogen resynthesis, especially since rapid resynthesis occurs within the first 2 hours after exercise. ${ }^{6,15-17}$ Other studies have reported higher glycogen resynthesis rates when a supplement was ingested more frequently as opposed to one large bolus. ${ }^{10,18}$

The research shows positive results for a post-exercise bolus feeding on glycogen resynthesis, recovery and performance. However, further research is needed to determine whether a postexercise feeding provided at more frequent time intervals during the recovery period could result in further improved performance. Discrepancies among study results may be due to the difference in

TABLE I. Summary of studies that investigated the effectiveness of a CHO-only beverage versus a CHO:PRO beverage on recovery and performance indices grouped according to year published

\begin{tabular}{|c|c|c|c|c|c|}
\hline Author (year) & Subjects $(N)$ & Protocol & Measures & Treatment & Results \\
\hline Carrithers, 2000 & 7 male collegiate cyclists & $\begin{array}{l}70 \% \text { max to exhaustion, } \\
\text { overnight rest, } 75 \mathrm{~m} \\
@ 70 \% \text { max to exhaus- } \\
\text { tion \& } 6 \times 1 \mathrm{~m} \text { sprints }\end{array}$ & $\begin{array}{l}\text { Muscle glycogen } \\
\text { Serum GLU } \\
\text { Serum insulin }\end{array}$ & $\begin{array}{l}\mathrm{CHO}, \mathrm{CHO}: \mathrm{PRO}, \\
\text { CHO:AA } \\
\text { Eucaloric }\left(1 \mathrm{~g}_{\mathrm{kg}}{ }^{-1} \mathrm{CHO}\right) \text {, } \\
\text { every } 30 \mathrm{~m} \text { for } 4 \mathrm{~h}\end{array}$ & $\begin{array}{l}\text { No diff. in muscle } \\
\text { glycogen or } \\
\text { performance }\end{array}$ \\
\hline Ivy, 2002 & 7 trained male cyclists & $\begin{array}{l}2.5 \text { h @ } 70 \% \text { max cycl., } \\
\text { Tx @ 1, } 2 \text { h post- } \\
\text { exercise }\end{array}$ & $\begin{array}{l}\text { Muscle GLY } \\
\text { Plasma insulin }\end{array}$ & $\begin{array}{l}\text { CHO: PRO (80:28) LCHO } \\
(80 \mathrm{~g}) \mathrm{H} \mathrm{CHO}(108 \mathrm{~g})\end{array}$ & $\begin{array}{l}\text { CHO:PRO sig. } \\
(p<0.05) \text { higher } \\
\text { GLY resynth }\end{array}$ \\
\hline Saunders, 2004 & 15 trained male cyclists & $\begin{array}{l}75 \% \text { max to exhaustion } \\
12-15 \text { h recovery } 85 \% \\
\text { max to exhaustion }\end{array}$ & CPK performance & $\begin{array}{l}\mathrm{CHO}(7.3 \%) \text { \& } \mathrm{CHO}: \mathrm{PRO} \\
(7.3 \%: 1.8 \%) \text { Given during } \\
\text { and post exercise }\end{array}$ & $\begin{array}{l}83 \% \text { lower CPK } \\
\text { in CHO:PRO, } \\
40 \% \text { longer TT } \\
\text { (CHO:PRO) }\end{array}$ \\
\hline Betts, 2005 & $\begin{array}{l}9 \text { (study A) } \\
7 \text { (study B) recreational } \\
\text { athletes }\end{array}$ & $\begin{array}{l}90 \text { min run @ } 70 \% \\
\text { max to exhaustion, } 4 \mathrm{~h} \\
\text { recovery }\end{array}$ & $\begin{array}{l}\text { Run time to exhaus- } \\
\text { tion @ 85\% max } \\
\text { Insulin response }\end{array}$ & 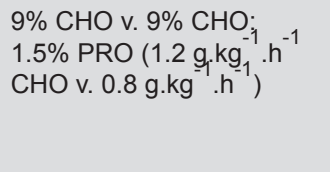 & $\begin{array}{l}\text { No diff. in per- } \\
\text { formance, sig. } \\
(p<0.05) \text { Greater } \\
\text { insulin response } \\
\text { w CHO:PRO }\end{array}$ \\
\hline Karp, 2006 & 9 trained male cyclists & $\begin{array}{l}\text { Interval workout } 4 \mathrm{~h} \\
\text { recovery } 70 \% \max \text { to } \\
\text { exhaustion }\end{array}$ & $\begin{array}{l}\text { Cycling performance } \\
\text { Total work RPE }\end{array}$ & $\begin{array}{l}\text { CHOC milk, FR (Gato- } \\
\text { rade), } \mathrm{CR}^{-1} \text { (Endurox): } \\
\left(1 \mathrm{~g} \cdot \mathrm{kg}^{-1} \cdot \mathrm{h}^{-1} \mathrm{CHO}\right) \text { for first } \\
2 \mathrm{~h} \text { post exercise }\end{array}$ & $\begin{array}{l}\text { TT \& total work } \\
\text { were sig. }(p<0.05) \\
\text { greater w FR and } \\
\text { choc milk }\end{array}$ \\
\hline Berardi, 2006 & $\begin{array}{l}6 \text { competitive male } \\
\text { cyclists }\end{array}$ & $\begin{array}{l}60 \text { min time trial }(\mathrm{am}) \\
6 \mathrm{~h} \text { recovery } \\
60 \text { min time trial }(\mathrm{pm})\end{array}$ & $\begin{array}{l}\text { Muscle } \\
\text { glycogen } \\
\text { Time trial perfor- } \\
\text { mance }\end{array}$ & $\begin{array}{l}\text { Isocaloric }\left(4.8 \mathrm{kcal} . \mathrm{kg}_{-1}^{-1}\right) \\
\mathrm{CHO} \text { : PRO (0.8 g.kg } \\
\left.0.4 \mathrm{~g}_{-1}^{-1}\right), \mathrm{CHO}(1.2 \\
\text { g.kg }), \mathrm{PLB} \text { for } 2 \mathrm{~h} \text { post } \\
\text { exercise, followed by solid } \\
\text { meal } 4 \text { h post }\left(7 \mathrm{kcal} . \mathrm{kg}^{-1}\right)\end{array}$ & $\begin{array}{l}\text { Liquid } \mathrm{CHO} \text { :PRO } \\
(p<0.05) \text { greater } \\
\text { gly synthesis dur- } \\
\text { ing recovery } \\
\text { No diff TT }\end{array}$ \\
\hline Luden, 2007 & $\begin{array}{l}23 \text { cross-country runners } \\
(11 \mathrm{M}, 12 \mathrm{~F})\end{array}$ & $\begin{array}{l}6 \text { d suppl. during } \\
\text { workout }\end{array}$ & $\begin{array}{l}\text { CPK } \\
5 \mathrm{k} \& 8 \mathrm{k} \\
\text { soreness }\end{array}$ & $\begin{array}{l}\text { CHO:PRO:A (1.4 g. } \mathrm{kg}^{-1} \\
\text { CHO, } 0.3 \mathrm{~g} \cdot \mathrm{kg}^{-1} \mathrm{PRO} \text {, Vit } \\
\text { C \& E), } \\
\left.\text { CHO (1.46 g. } \mathrm{kg}^{-1}\right): 30 \\
\text { min post exercise }\end{array}$ & $\begin{array}{l}\text { Sig. }(p<0.05) \\
\text { lower CPK, \& } \\
\text { soreness in } \\
C: P: A . \text { No diff. in } \\
\text { performance }\end{array}$ \\
\hline
\end{tabular}


protocols used, timing and interval of post-exercise recovery meals, training status of subjects, and form of $\mathrm{CHO}$. Therefore, considering these limitations and inconsistency among the research protocols, current research suggests that $1.0-1.5 \mathrm{~g}_{\mathrm{kg}} \mathrm{kg}^{-1}$ of $\mathrm{CHO}$ is sufficient for maximal glycogen resynthesis. ${ }^{1,3,4}$ More studies are needed that examine the effects of a post-exercise feeding over time and that simulate a normal training programme.

\section{Addition of protein to $\mathrm{CHO}$ in a recovery meal}

The literature concerning the effects of post-exercise ingestion of a $\mathrm{CHO}-\mathrm{PRO}$ supplement compared with a $\mathrm{CHO}$ supplement (i.e. sports beverage) on performance is inconsistent. Some studies show improved performance with the $\mathrm{CHO}-\mathrm{PRO}$ complex versus a $\mathrm{CHO}$ only, ${ }^{11,13,16-21}$ while others show no difference in performance. ${ }^{5,22-24}$ It should be noted that the majority of the literature has examined recovery in trained cyclists or runners when performing a time trial to exhaustion at $70-85 \%$ of $\mathrm{VO}_{2 \max }{ }^{5,11,13,16,20-24}$ Table I provides a summary of several studies that have investigated the effectiveness of a $\mathrm{CHO}$-only beverage versus a $\mathrm{CHO}: \mathrm{PRO}$ beverage on recovery indices.

\section{Protein and muscle glycogen resynthesis}

Protein contributes an estimated $5-15 \%$ of total energy expenditure during endurance exercise ${ }^{25}$ which is considerably less than the contribution of carbohydrate. Berardi et al. found a significant $(p<0.05)$ improvement in glycogen resynthesis during a 6-hour recovery following a 60-minute cycling time trial with CHO:PRO (0.8 g. $\mathrm{kg}^{-1} \mathrm{CHO}, 0.4$ g.kg ${ }^{-1} \mathrm{PRO}$ ) in male cyclists (CHO:PRO 28.6 \pm 2.1 mmol. $I^{-1}$ v. CHO $22.2 \pm 1.1 \mathrm{mmol}^{-1} \mathrm{I}^{-1}$ ), while Betts et al. found a significant $(p<0.05)$ increase in insulinaemic response with CHO:PRO trial (CHO:PRO 13.5 $\pm 1.1 \mathrm{mIU}^{2} 240 \mathrm{~min}^{-1} . \mathrm{ml}^{-1} \mathrm{v}$. CHO $11.4 \pm 0.9 \mathrm{mIU}$ $240 \mathrm{~min}^{-1} \cdot \mathrm{ml}^{-1}$ ) during a 4-hour recovery after 90 minutes of running at $70 \%$ of $\mathrm{VO}_{2 \max }$ in active runners. ${ }^{5,22}$ However, neither of these studies found a difference in performance during a run time to exhaustion at $85 \%$ of $\mathrm{VO}_{2 \max }{ }^{22}$ or a 60 -minute time cycling time trial5 between the $\mathrm{CHO}: \mathrm{PRO}$ and $\mathrm{CHO}-$ only trials. These findings are similar to other studies ${ }^{6,15-17}$ which have reported improved glycogen repletion following post-exercise $\mathrm{CHO}-\mathrm{PRO}$ supplementation (at a 2 - 2.9:1 ratio of CHO-to-protein). ${ }^{1}$ Berardi et al. speculated that the self-selected intensity used in the time trial for this study may have impacted performance outcomes. ${ }^{5}$ A controlled intensity may have been more beneficial. Betts et al. suggested that factors such as protein content, frequency of supplementation, and factors other than carbohydrate availability such as acidosis, which are related to fatigue, may have affected performance. ${ }^{22}$

These findings are similar to the earlier-reported studies indicating improved glycogen repletion following post-exercise $\mathrm{CHO}$ PRO supplementation compared with $\mathrm{CHO}$ only, ${ }^{6,15-17}$ while others have observed no effects. ${ }^{5,9,22,23,26}$ Contrary to these findings, Ivy et al. found that consuming $200 \mathrm{ml}$ of a solution with a $4: 1$ ratio of CHO-PRO (7.75\% CHO/1.94\% PRO) every 20 minutes during the recovery period enhanced cycling endurance performance by $36 \%$ in trained cyclists versus a CHO-only $(7.75 \% \mathrm{CHO})$ solution. Reasons for these performance differences among the studies are inconclusive. However, the authors speculated that the results of this study may have been related to maintenance of plasma amino acid levels as it relates to the (branched chain amino acid) central fatigue hypothesis, sparing of muscle glycogen, or retention of Krebs' cycle intermediates. ${ }^{20}$

Decreased muscle glycogen levels are closely related to fatigue during exercise. ${ }^{16}$ The addition of protein to a $\mathrm{CHO}$ beverage would be practically important if it further increased performance and enhanced recovery between exercise sessions with a short recovery period. Current research has examined the impact after intense exercise of adding protein (PRO) ( $20 \%$ of total calories) to a carbohydrate beverage on muscle glycogen resynthesis. Prior research suggested that the addition of protein to a post-exercise carbohydrate beverage enhanced glycogen resynthesis due to an increase in insulin levels, thereby enhancing glucose deposits in the muscle. $3,6,17,23$ However, it should be noted that the aforementioned investigations were not eucaloric between the beverages. Recently, when the energy content of the protein is matched in the beverages, some of these findings regarding the increase in glycogen resynthesis have been refuted. ${ }^{3}$

Carrithers et al. found no difference in muscle glycogen resynthesis rates when comparing three post-exercise eucaloric ( $\mathrm{CHO}, \mathrm{CHO}$ :PRO, versus a $\mathrm{CHO}$ :amino acid) beverages administered every 30 minutes during a 4-hour recovery in male collegiate cyclists after a glycogen depletion ride on a cycle ergometer. ${ }^{23}$

In contrast, Ivy et al. suggested that consumption of a post-exercise CHO:PRO (80 g CHO, $28 \mathrm{~g}$ PRO, and $6 \mathrm{~g}$ fat) beverage enhanced early post-exercise muscle glycogen resynthesis rates after 2.5 hours cycling at $70 \%$ of $\mathrm{VO}_{2 \max }$ when compared with a high $\mathrm{CHO}$ only (108 $\mathrm{g} \mathrm{CHO}$, and $6 \mathrm{~g}$ fat), and low $\mathrm{CHO}$-only $(80 \mathrm{~g} \mathrm{CHO}$, and $6 \mathrm{~g}$ fat) beverage. In addition, there were no differences in post-exercise insulin concentrations among the three treatments; however, postexercise plasma glucose concentrations were significantly lower with the CHO:PRO beverage. The authors speculated that the increase in muscle glycogen restoration and decrease in plasma glucose concentrations with a $\mathrm{CHO}$ PRO beverage may signify enhanced glucose uptake and relocation of intracellular glucose disposal. ${ }^{15}$ Furthermore, the addition of protein to a post-exercise recovery meal may be beneficial if carbohydrate consumption is below the threshold $\left(<1 \mathrm{~g} \cdot \mathrm{kg}^{-1}\right)$ for maximal glycogen replacement. ${ }^{3}$

\section{Protein and muscle recovery}

The addition of protein to a post-exercise recovery meal may also enhance net protein anabolism. ${ }^{13}$ During the post-exercise period, there is an increased rate of muscle protein synthesis in trained individuals. $^{3}$ The results of literature ${ }^{6,15-17}$ seem to be in support of the addition of protein to the recovery beverage. In addition, studies have reported decreases in muscle damage (CPK) with the addition of PRO to a recovery beverage after exercise sessions. $8,13,21,25,27,28$ Both high-intensity and prolonged endurance exercise can damage skeletal muscle, resulting in delayed-onset muscle soreness with concurrent increases in markers of muscle damage such as creatine kinase ( $\mathrm{CK}$ ), myoglobin (Mb), cortisol and lactate dehydrogenase $(\mathrm{LDH}) .{ }^{29,30}$ Elevated levels of these enzymatic markers are associated with decreased performance. ${ }^{30}$ Due to the applied nature of recovery studies, the majority of the literature examining muscle damage has included multiple indicators of muscle damage: bloodborne creatine kinase (CK), subjective measures of muscle soreness (using a visual scale). ${ }^{31}$ However, CK has been criticised as an effective indicator of muscle damage because of poor correlations with direct measures of muscle damage.

Research that has examined subsequent exercise performance and muscle damage suggests that a $\mathrm{CHO} P \mathrm{PRO}$ v. a $\mathrm{CHO}-$ only beverage ingested during and after exercise may positively influence recovery. ${ }^{13,21,25,32}$ Saunders et al. found that the addition of protein to a carbohydrate replacement beverage taken during and after exercise resulted in $83 \%$ lower CK levels 12 - 15 hours after endurance cycling at $85 \%$ of $\mathrm{VO}_{2 \max }$ when compared with a $\mathrm{CHO}$ - 
only beverage in trained cyclists. In addition, cyclists performed $40 \%$ longer following the consumption of a $\mathrm{CHO}$ :PRO beverage. ${ }^{13}$ However, it should be noted that the amount of calories between the two beverages were not equivalent (CHO:PRO 581 kcals; $\mathrm{CHO} 391$ kcals). Another study that compared the ingestion of $\mathrm{CHO}$ :PRO gels with $\mathrm{CHO}$-only gels during and after a cycling trial at $70 \%$ of $\mathrm{VO}_{2 \max }$ to exhaustion in cyclists, found that $\mathrm{CK}$ levels were significantly increased $(p<0.05)$ post exercise with the CHO-only trial ((pre) $183 \pm 116{\mathrm{U} . I^{-1}}^{-1}$, (post) $267 \pm 214 \mathrm{U.I}^{-1}$ ) compared with the combined CHO:PRO trial ((pre)180 $1133 \mathrm{U.I}^{-1}$, (post) $222 \pm 141 \mathrm{U.I}^{-1}$ ). ${ }^{25}$ These findings are similar to a study by Romano et al., who found that consumption of a CHO:PRO:antioxidants (CHO:PRO:A) v. a CHOonly beverage during and after two consecutive rides to exhaustion (the first ride at $70 \%$ of $\mathrm{VO}_{2 \max }$, followed by a second ride at $80 \%$ of $\left.\mathrm{VO}_{2 \max }\right)$ significantly $(p<0.05)$ attenuated levels of $\mathrm{CK}(\mathrm{CHO}$ : (pre) $203 \pm 120 \mathrm{U.I}^{-1}$, (post) 582 $\pm 475 \mathrm{U.I}^{-1}$, and CHO:PRO:A (pre) 188 \pm 119 $U . I^{-1}$ v. $\left.273 \pm 169 U^{-1} I^{-1}\right)$, as well as lactate dehydrogenase (LDH), and subjective muscle soreness using a 5-point scale ( $\mathrm{CHO} 3.0 \pm 5.0$, and CHO:PRO:A 1.0 \pm 3.0 ) after exercise. ${ }^{8}$ The two beverages used in this study were matched for caloric content. It is unclear whether decreases in muscle damage and improvements in performance would be seen with post-exercise feedings alone ${ }^{31}$ compared with feedings given both during, and after the workout. It should be noted that subjects supplemented both during and post exercise in most aforementioned studies.

Recently, chocolate milk has been suggested to be an effective, but lower-cost recovery aid due to a $\mathrm{CHO}$ :PRO ratio similar to many commercial recovery and carbohydrate-replacement beverages. Chocolate milk is composed of monosaccharides (glucose and fructose) and disaccharides (lactose), while the commercially available recovery beverage consists of monosaccharides (glucose and fructose) and complex carbohydrates (maltodextrin). Based on the recommendations (4) regarding post-exercise $\mathrm{CHO}$ intake, a 70$\mathrm{kg}$ male, would need to consume $510-810 \mathrm{ml}(70-84 \mathrm{~g} \mathrm{CHO}$, and 19 - $30 \mathrm{~g}$ PRO) and a 60-kg female 435 - $690 \mathrm{ml}$ (60 - $72 \mathrm{~g} \mathrm{CHO}$ and 16 - $26 \mathrm{~g}$ PRO) of low-fat chocolate milk per hour. Karp et al. examined the effectiveness of consuming chocolate milk $(\mathrm{CHOC})$ as a postexercise recovery aid between two cycling sessions in trained cyclists. After 4 hours of recovery, cycling time to exhaustion at $70 \%$ of $\mathrm{VO}_{2 \max }$ was significantly longer for the chocolate milk trial (by $\sim 15$ minutes) compared with the recovery beverage (Endurox R4, PacificHealth Labratories, Woodbridge, NJ) trial. ${ }^{11}$ The differences in performance demonstrated in this study may have been attributed to the different types of carbohydrate in the beverages. Because increases in muscle glycogen levels during the early hours of recovery are greater with simple v. complex carbohydrate, ${ }^{33}$ perhaps the 4-hour recovery period did not allow enough time for the complete digestion of the complex carbohydrates in the recovery beverage. The authors of this study also speculated whether the higher fat content of chocolate milk may have increased the levels of free fatty acids in the blood, possibly delaying glycogen depletion during the subsequent cycling trial to exhaustion and allowing subject to cycle longer. ${ }^{11}$ However, when post-exercise consumption of $\mathrm{CHOC}$ was compared with an isocaloric

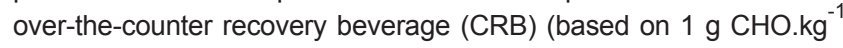
of body weight/ hour post-exercise for the first 2 hours) after a highintensity fatiguing trial, the authors found no differences in cycling time to exhaustion at $85 \%$ of $\mathrm{VO}_{2 \max }{ }^{27}$

Pritchett et al. compared the post-exercise consumption of chocolate milk $(\mathrm{CHOC})$ to an over-the-counter recovery beverage (CRB) matched for $\mathrm{CHO}$ PRO content and found creatine kinase $(\mathrm{CK})$ was significantly $(p<0.05)$ greater in the CRB trial compared

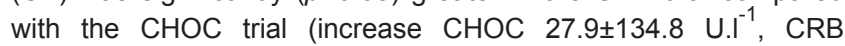

211.9 $\left.\pm 192.5 \mathrm{U} . \mathrm{I}^{-1}\right)$; with differences not significant for CK post (CHOC $394.8 \pm 166.1$ U.I $^{-1}$, CRB 489.1 \pm 264.4 U.I $^{-1}$ ) between the two trials. ${ }^{27}$ Furthermore, a recent study found similar improvements in endurance performance between a $\mathrm{CHO}: \mathrm{PRO}$ and a CHO-only beverage when matched for total kilocalories. Also, lower plasma $\mathrm{CK}$ levels were observed in the CHO:PRO v. CHO-only trial. ${ }^{21}$

The majority of studies only examined a single-dose recovery beverage ingested post exercise on muscle damage and performance but did not examine chronic training effects. The potential benefits of the recovery aid may be insignificant if not given adequate time to be effective, especially in highly trained athletes. More recent studies have examined a post-exercise nutritional beverage taken over time (6 days) on muscle damage. Luden et al. found significantly $(p<0.05)$ lower CK levels with a CHO:PRO:A beverage $\left(223.21 \pm 160.7 \mathrm{U.I}^{-1}\right)$ versus the $\mathrm{CHO}$ - only beverage $\left(307.3 \pm 312.9 \mathrm{U} . \mathrm{I}^{-1}\right)$. Muscle soreness, using a visual analog scale, was also reported to be significantly $(p<0.05)$ lower after 5 days of post-exercise supplementation with the CHO:PRO:A beverage (1.0 VAS) v. the $\mathrm{CHO}$ only beverage (2.0 VAS). However, the effect of protein on protein synthesis and protein degradation in this study cannot be ruled out. It is not evident whether the results of this study were due to supplementation during exercise, after exercise, or in combination. The authors offered that it cannot be ruled out that the attenuation in CK levels may be due to the additional calories, or improvements in protein synthesis with the CHO:PRO:A beverage. ${ }^{26}$

Similarly, Skillen et al. reported decreases in CK levels and fatigue following 90 minutes of cycling at $75 \%$ of $\mathrm{VO}_{2 \max }$ followed by a time trial to exhaustion at $85 \%$ of $\mathrm{VO}_{2 m a x}$ after 2 weeks of supplementation in cyclists with a $3.6 \% \mathrm{CHO} \pm 1 \%$ amino acid solution. ${ }^{32}$ Gilson et al. examined the effectiveness of low-fat chocolate milk versus a high $\mathrm{CHO}$ recovery beverage consumed after exercise for a week in intercollegiate soccer players. ${ }^{34}$ The soccer players continued their normal training regimen (which was similar among subjects). Similar to the findings of Luden et al., ${ }^{31}$ this study found significantly $(p<0.05)$ lower CPK (CHOC: $316.9 \pm 188.3$ U.I $^{-1}$, CHO:431.6 \pm 310.8 U. $^{-1}$ ) levels after one week of supplementation with a beverage containing protein (chocolate milk) v. a high $\mathrm{CHO}-$ only beverage. However, no differences in performance were reported between beverages. ${ }^{34}$

In conclusion, post-exercise recovery beverages containing protein seem to be effective in improving recovery indices. However, some of the results may be due to the higher caloric content of the CHO:PRO supplements. The additional protein calories via glucogenesis may have provided additional substrate for glycogen resynthesis to occur, therefore aiding in an enhanced recovery. ${ }^{12}$ Currently research suggests that $20-25 \mathrm{~g}$ of high-quality protein during a single feeding is optimal. Future research should examine the type of protein, timing of intake, and the effects of distribution of protein throughout the day on recovery indices. ${ }^{3}$

\section{Type of recovery meals}

Research examining the effects of a post-exercise feeding has exclusively supplemented with a beverage or solid rather than a gel feeding. One reason for this may be that gels are typically consumed during endurance exercise. It appears that the same benefits would be observed with a meal that is in the form of a solid or liquid feeding. ${ }^{3}$ Consequently, current recommendations are based on research that has examined recovery meals in liquid or solid form.

To our knowledge, one study has examined the effects of a postexercise $\mathrm{CHO}$-only oral gel versus a $\mathrm{CHO}$ :PRO oral gel on endurance performance and muscle damage. Saunders et al. compared the effectiveness of a CHO:PRO gel to a CHO-only gel consumed 
during and after exercise on muscle damage and performance measures. In a cycling time trial to volitional exhaustion at $75 \%$ of $\mathrm{VO}_{2}$ peak, subjects cycled $13 \%$ longer $(p<0.05)$ with the $\mathrm{CHO}$ :PRO gel compared with the $\mathrm{CHO}$-only gel. Also, $\mathrm{CK}$ levels significantly increased $(p<0.05)$ after exercise with the $\mathrm{CHO}$-only gel compared with the $\mathrm{CHO}: \mathrm{PRO}$ gel. $^{25}$

\section{Limitations of studies}

Various limitations have been discussed throughout the studies that have examined post-exercise nutritional strategies for optimal recovery. The vast majority of the studies examined the acute effects of post-exercise recovery on exercise performance. Practically it would be more beneficial to examine the effects of these nutritional strategies over a longer duration similar to a training regimen.

Extraneous variables such as dietary intake and sleep patterns were often not controlled in the studies. In order to examine the effect of a recovery beverage on performance and recovery, it is vital to control for dietary intake. It is ideal to provide a food frequency questionnaire as well as a 3-day food record to get an accurate depiction of diet. Sleep is another variable that could influence the results of study, therefore variations in sleep patterns should be considered when comparing trials.

Over the past 5 years, evidence has suggested a CHO:PRO beverage may be more beneficial in enhancing endurance performances compared with a $\mathrm{CHO}$-only beverage. ${ }^{35} \mathrm{~A}$ major concern that has been addressed in a number of the studies is the inconsistency of the calories between treatments (i.e. $\mathrm{CHO}$ v. $\mathrm{CHO}$ :PRO beverages). Providing isocaloric beverages would be beneficial in determining whether it is the addition of protein, or the additional calories, that are responsible for the results.

Research on post-exercise nutritional strategies has primarily been done on males. A study by Tarnopolsky et al. suggested males oxidise higher proportion of carbohydrate during exercise than females. ${ }^{36}$ Therefore, recommendations that have been established may only be effective for males and should be examined in females.

\section{Future research}

Future research should examine isocaloric beverages when comparing beverages of different compositions on recovery. Because it is ideal to incorporate a recovery beverage into athletes' daily regimens, it would be more beneficial to the athletic population to examine the effectiveness of a post-exercise recovery beverage taken on a daily basis.

Future research should examine other measures of muscle damage. Creatine phosphokinase and subjective measures of muscle soreness have been the primary dependent variables in the literature. Due to the variable nature of $\mathrm{CK}$, measuring other blood parameters such as LDH, myoglobin and cortisol in conjunction with CK would enhance the quality of the studies.

It has also been noted that frequent post-exercise feedings may be beneficial in enhancing glycogen resynthesis. Perhaps providing glucose at a metered rate rather than as a bolus would provide higher plasma glucose and insulin levels, resulting in enhanced glycogen resynthesis. ${ }^{1}$ Therefore research should examine differences in a metered post-exercise feeding $\mathrm{v}$. a large bolus feeding.

Many athletes, particularly cyclists, consume foods in solid or gel forms during workout or competition. For practical purposes, research should examine differences in solid, liquid and gel forms of recovery meals on muscle glycogen resynthesis, and other recovery measures.

\section{Practical applications}

The literature that is available regarding post-exercise nutritional strategies for optimal performance is evolving. We suggest that the optimal timing regarding post-exercise nutritional strategies for maximal glycogen resynthesis is within the first 2 hours after exercise. ${ }^{6,15-17}$ Also, the literature suggests that $1.0-1.5 \mathrm{~g} \cdot \mathrm{kg}^{-1} \cdot \mathrm{h}^{-1}$ may be optimal for recovery. ${ }^{1,11,15}$ The addition of $20-25 \mathrm{~g}$ of high-quality protein to a recovery meal may aid in muscle protein resynthesis. ${ }^{3,6,15-17}$

\section{REFERENCES}

1. Jentjens RL, Jeukendrup AE. Determinants of post-exercise glycogen synthesis during short term recovery. Int J Sport Nutr Exerc Metab 2003;33(2):117-144.

2. Burke L. Fasting and recovery from exercise. Br J Sports Med 2010;44:502508.

3. Bishop PA, Jones, E, Woods K. Recovery from Training: A Brief Review. J Strength Cond Res 2008;229(3):1-10.

4. American College of Sports Medicine, American Dietetic Association, and Dietitians of Canada. Nutrition and Athletic Performance. Joint Position Statement of the American Dietetic Association, Dietitians of Canada, and the Medicine and American College of Sports Medicine. Med Sci Sports Exerc 2009;109:509-527.

5. Berardi JM, Price TB, Noreen EE, Lemon PWR. Postexercise muscle glycogen recovery enhanced with carbohydrate-protein supplement. Med Sci Sports Exerc 2006;38(6):1106-1113.

6. Van Loon LJ, Saris WM, Ruijshoopanda MK, Wagenmakers AM. Maximizing postexercise muscle glycogen synthesis: Carbohydrate supplementation and the application of amino acid or protein hydrolysate. Am J Clin Nutr 2000;72:106-111.

7. Ryans M. Sports Nutrition for Endurance Athletes, 2nd ed. Boulder, CO: Velopress, 2007.

8. Romano-Ely BC, Todd K, Saunders MJ, St. Laurent T. Effect of an Isocaloric Carbohyrdrate-Protein-Antioxidant Drink on Cycling Performance. Med Sci Sports Exerc 2006;38(9):1608-1616

9. Van Hall G, Shirreffs SM, Calbert JAL. Muscle glycogen resynthesis during recovery from cycle exercise: no effect of additional protein ingestion. J Appl Physiol 2000;88:1631-1636.

10. Doyle JA, Sherman WM, Strauss RL. Effects of eccentric and concentric exercise on muscle glycogen replenishment. J Appl Physiol 1993; $74: 1848-1855$

11. Karp JR, Johnston JD, Tecklenburg S, Mickleborough TD, Fly AD, Stager JM. Chocolate milk as a post-exercise recovery aid. Int J Sport Nutr Exerc Meta 2006;16:78-91.

12. Ivy JL, Katz AL, Cutler CL. Muscle glycogen synthesis after exercise: effect of time of carbohydrate ingestion. J Appl Physiol 1988;64(4):14801485.

13. Saunders MJ, Kane MD, Todd MK. Effects of carbohydrate-protein beverage on cycling endurance and muscle damage. Med Sci Sport Exerc 2004;36(7):1233-1238.

14. Blom, PCS. Effect of different post-exercise sugar diets on the rate of glycogen synthesis. Med Sci Sports Exerc 1987;19(5):491-496.

15. Ivy JL, Goforth HW, Damon BM, McCauley TR, Parsons EC, Price TB. Early postexercise muscle glycogen recovery is enhanced with a carbohydrate-protein supplement. J Appl Physiol 2002;93:1337-1344.

16. Williams MB, Raven PB, Fogt DL, Ivy JL. Effects of recovery beverages on glycogen restoration and endurance exercise performance. J Strength Cond Res 2003;17:12-19.

17. Zawadzki KM, Yaspelkis BB, Ivy JL. Carbohydrate-protein complex increases the rate of muscle glycogen storage after exercise. J Appl Physiol 1992;72:1854-1859.

18. Van Hall G, Saris WHM, Wagenmakers AJM. Effect of carbohydrate supplementation on plasma glutamine during prolonged exercise and recovery. Int J Sports Med 1998;19:82-86.

19. Berardi JM, Noreen EE, Lemon PWR. Recovery from a cycling time trial is enhanced with carbohydrate-protein supplementation vs. isoenergetic carbohydrate supplementation. J Inter Soc Sports Nutr 2008; 5(24).

20. Ivy JL, Res PT, Sprague RC, Widzer MO. Effect of a carbohydrate-protein supplement on endurance performance during exercise of varying intensity. Int J Sport Nutr Exerc Metab 2003:13(3):382-395.

21. Valentine RJ, Saunders MJ, Todd MK, St. Laurent TG. Influence of carbohydrate-protein beverage on cycling endurance and indices of muscle disruption. Int J Sports Nutr Exerc Metab 2008;18:379-388.

22. Betts JA, Stevenson E, Williams C, Steppard C, Grey E, Griffin J. Recovery of endurance running capacity: effect of carbohydrate-protein mixtures. Int J Sport Nutr Exerc Metab 2005;15:590-609.

23. Carrithers JA, Williamson DL, Gallagher PM, Godard MP, Schulze KE, Trappe SW. Effects of postexercise carbohydrate-protein feedings on muscle glycogen restoration. J Appl Physiol 2000;88:1976-1982. 
24. Green MS, Corona BT, Doyle JA, Ingalls CP. Carbohydrate-protein drinks do not enhance recovery from exercise-induced muscle injury. Int $J$ Sports Nutr Exerc Metab 2008;18:1-18.

25. Saunders MJ, Luden ND, Herrcick JE. Consumption of an oral carbohydrate-protein gel improves cycling endurance and prevents postexercise muscle damage. J Strength Cond Res 2007;21(3):678-684.

26. Jentjens RLPG, van Loon LJ, Mann CH, Wagenmakers AM, Jeukendrup AE. Addition of protein and amino acids to carbohydrates does not enhance postexercise muscle glycogen synthesis. J Appl Physio 2001;:93:839-846.

27. Pritchett KL, Bishop PA, Pritchett RC, Green JM, Katica C. Acute effects of chocolate milk and a commercial recovery beverage on post-exercise muscle damage and cycling performance. J Appl Phys Nutr \& Metab 2009;34(6):1017-1022.

28. Ready SL, Seifert JL, Burke E. The effects of two sports drinks formulations on muscle stress and performance. Med Sci Sports Exerc 1999;31:S119.

29. Clarkson PM, Kearns AK, Rouzier P, Rubin R, Thompson PD. Serum creatine kinase levels and renal function measures in exertional muscle damage. Med Sci Sports Exerc 2006;38(4):623-627.

30. White JP, Wilson JM, Austin KG, Greer BK, St. John N, Panton LB. Effect of a carbohydrate-protein supplement timing on acute exercise-induced muscle damage. J Int Soc Sports Nutr 2008;5(5)
31. Luden ND, Saunders MJ, Todd K. Postexercise carbohydrate-proteinanitoxidant ingestion decreases plasma creatine kinase and muscle soreness. Int J Sport Nutr Exerc Met 2007;17:109-123.

32. Skillen RA, Testa M, Applegate EA, Heiden EA, Fascetti AJ, Casazza GA. Effects of an amino acid - carbohydrate drink on exercise performance after consecutive-day exercise bouts. Int J Sport Nutr Exerc Metab 2008;18:473-492

33. Freidman JE, Neufer PD, Dohm GL. Regulation of glycogen resynthesis following exercise. Sports Med 1991;11(4):232-243.

34. Gilson S, Suanders MJ, Moran C, Moore R, Womack CJ, Todd K. Effects of chocolate milk consumption on markers of recovery following soccer training: a randomized cross-over study. J Inter Soc Sports Nutr 2010;7(19).

35. Baty JJ, Hwang H, Ding Z, Bernard JR, Wang B, Kwon B, Ivy JL. The effect of a carbohydrate and protein supplement on resistance exercise performance, hormonal response, and muscle damage. J Strength Cond Res 2007;21(2):321-329.

36. Tarnopolsky MA, Bosman M, Macdonald JR, Vandeputte D, Marti J, Roy BD. Postexercise protein-carbohydrate and carbohydrate supplements increase muscle glycogen in men and women. J Appl Physiol 1997;83(6):1877-1883. 